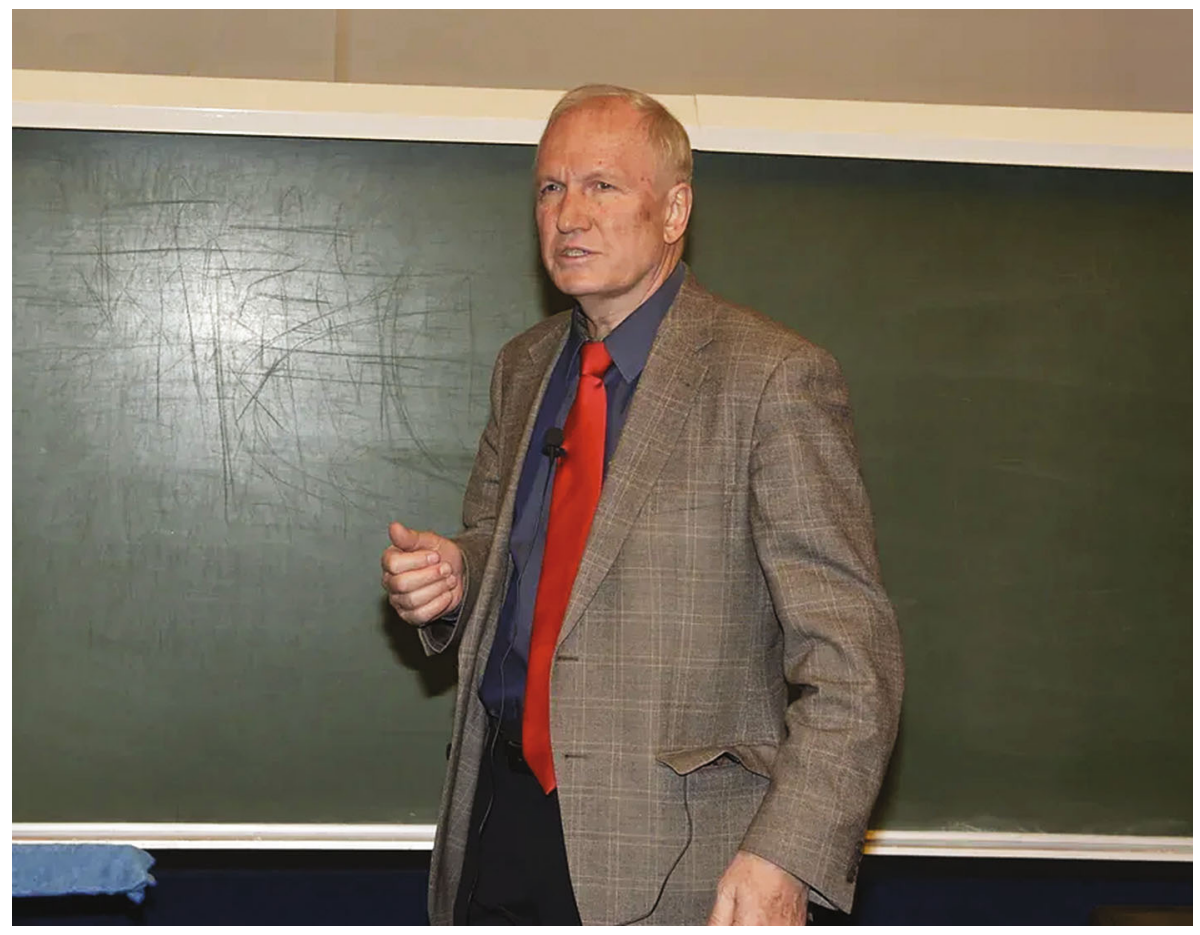

\title{
Valery V. Kozlov \\ On the Occasion of his 70th Birthday
}

DOI: $10.1134 / \mathrm{S} 1560354720010013$

On January 1, 2020, the outstanding Russian mathematician Valery V. Kozlov had his 70th birthday. The editorial staff cordially congratulates Valery Kozlov on his birthday and wishes him good health and new scientific achievements! This special issue includes papers by his followers and colleagues who are sincerely grateful to him for inspiration and unabated interest in their research work.

Editorial Board 